DOI 10. 18307/2017. 0302

(C) 2017 by Journal of Lake Sciences

\title{
滇池蓝藻水华发生频率与气象因子的关系
}

\author{
鲁韦坤 ${ }^{1,2}$, 余凌翔 ${ }^{2}$, 欧晓昆 ${ }^{1}$, 李发荣 ${ }^{3}$ \\ (1: 云南大学生态学与地植物学研究所, 昆明 650091) \\ (2:云南省气候中心, 昆明 650034) \\ (3: 昆明市环境监测中心, 昆明 650032)
}

\begin{abstract}
摘 要: 蓝藻水华暴发是在一定的营养、气候、水文条件和生态环境下形成的藻类过度繁殖和聚集的现象, 是水体环境 因子 (如总氮、总磷、pH 值、溶解氧) 和气象因子综合作用的结果. 然而滇池周年性水华暴发标志着滇池蓝藻水华在当前 水质条件下, 气象因子为关键影响因子. 为了进一步探究滇池蓝藻水华发生与气象因子的规律, 本文利用 2010-2011 年 滇池蓝藻水华遥感监测资料与周边地面气象站逐月资料, 研究滇池蓝藻水华月发生频率与月气象因子的关系. 结果显 示, 滇池蓝藻水华发生频率与平均气温、最低气温、平均风速、累计日照时数和降雨量等气象因子均表现为显著相关, 其 中与日照时数和风速呈显著负相关. 各因子中与风速的相关系数最高, 说明滇池各月蓝藻水华发生频率高低与风速关系 最为密切, 进一步验证了在具备蓝藻水华发生所需营养盐条件下, 水体稳定性对蓝藻水华发生的影响更为重要的结论. 以上结果可为科学预测蓝藻水华发生,并采取相应措施减少其带来的影响提供理论依据.
\end{abstract}

关键词: 滇池;蓝藻水华;遥感;气象因子;环境因子

\section{Relationship between occurrence frequency of cyanobacteria bloom and meteorological factors in Lake Dianchi}

\author{
LU Weikun ${ }^{1,2}$, YU Lingxiang ${ }^{2}$, OU Xiaokun ${ }^{1} \&$ LI Farong ${ }^{3}$ \\ (1: Institute of Ecology and Geobotany, Yunnan University, Kunming 650091, P.R.China) \\ (2: Yunnan Climate Center, Kunming 650034, P.R. China) \\ (3: Kunming Environment Monitor Center, Kunming 650032, P.R.China)
}

\begin{abstract}
The published study suggested that cyanobacteria bloom was a phenomenon of excessive reproduction and aggregation with certain nutrient levels, climate and hydrological conditions and was the result of the comprehensive effect of meteorological and water environmental factors such as total nitrogen, total phosphorus, $\mathrm{pH}$ values. It was also found that annual outbreak of cyanobacteria bloom in Lake Dianchi indicated that, under the current condition of water quality, the main factor was the meteorological factor. In order to further explore the regularity between meteorological factors and occurrence of cyanobacterial bloom, the relationship between frequency of cyanobacteria bloom and meteorological factors were studied, by using the remote sensing data of cyanobacteria bloom and the monthly meteorological data from the stations nearby Lake Dianchi from 2010 to 2011 . The results showed that the cyanobacterial bloom frequency had significant correlation with the average temperature, minimum temperature, average wind speed, cumulative sunshine hours and precipitation, which had a significant negative correlation with sunshine hours and wind speed, respectively. Among the factors, the wind speed had the highest correlation coefficient. It showed that the weaker wind speed was the most closely related to the occurrence of cyanobacteria bloom in Lake Dianchi. And this further verified that the stability of the water body had a more important effect on the occurrence of cyanobacteria bloom, under certain conditions of sufficient nutrients for requires of cyanobacteria bloom. These results can be used as a scientific prediction to forecast the occurrence of cyanobacteria bloom, and to take appropriate measures to reduce the impact of the cyanobacteria bloom.
\end{abstract}

Keywords: Lake Dianchi; cyanobacteria bloom; remote sensing; meteorological factors; environmental factors

* 国家水体污染控制与治理科技重大专项(2010ZX07102-006) 和云南省社会事业发展专项 (2011CA014) 联合资助. 2016-04-04 收稿;2016-08-22 收修改稿. 鲁韦坤( 1979 ), 男, 硕士, 高级工程师; E-mail : luweikun@ hotmail. com. 
藻类水华暴发是在一定的营养、气候、水文条件和生态环境下形成的藻类过度繁殖和聚集的现象, 是水 体环境因子 (如总氮 ( TN)、总磷 (TP)、 $\mathrm{pH}$ 值、水动力、溶解氧) 和气象因子 (如气温、光照、风速等) 综合作用 的结果 ${ }^{[1-2]}$. 一般认为较高的氮、磷等营养盐浓度 ${ }^{[3-4]}$ 以及较低的氮磷比 ${ }^{[5-7]}$ 、较高的水温 ${ }^{[8-9]}$ 、充足的光照 ${ }^{[9-11]}$ 以及较小的风速和风浪条件 ${ }^{[9,11-15]}$ 都有可能促成蓝藻水华暴发 ${ }^{[16]}$. 对滇池而言, 2001 年首次出现周年性水 华, 标志着滇池蓝藻水华在当前水质条件下, 气象因子为关键影响因子. 因此, 有必要针对气象条件对滇池 蓝藻水华发生的影响进行分析. 其结果可作为科学预测藻类水华的产生, 并采取相应措施减少其带来影响 的理论依据,具有重要的生态和环境意义.

\section{1 资料和方法}

\section{1 滇池蓝藻水华的月发生频率}

1.1.1 蓝藻水华的定义 目前“水华”没有一个国际公认的定义, 现有文献中关于水华的定义综合后主要有 以下几种观点: (1) 藻细胞密度为 $0.5 \times 10^{6} \sim 15 \times 10^{6} \mathrm{cells} / \mathrm{L}^{[17]} ;$; (2) 水体藻类大量生长繁殖或聚集并达到一 定浓度 ${ }^{[18]} ;$ ( 3) 某些藻类发生性的繁殖, 引起明显的水色变化, 并在水面形成或薄或厚的绿色或其他颜色的 藻类漂浮物 ${ }^{[19]}$. 就第一种观点而言, 滇池 2010-2011 年 8 个常规水质观测点的藻密度月平均最小值为 $2.1 \times$ $10^{7} \mathrm{cells} / \mathrm{L}$, 依据该定义, 滇池全年都在发生水华, 这显然与媒体和公众所认知的水华实际情况不符. 后两种 观点的差异主要体现在 “聚集” 描述上的差异, 其中第 3 种观点明确指出必须在水面形成或薄或厚的绿色或 其他颜色藻类的漂浮物才能称之为水华, 这一观点为遥感监测水华大多数相关文献和媒体所认可. 同时对 于遥感而言, 该定义有利于将水华区域光谱特征区别于无水华区域, 遥感监测结果更加准确可信. 综上所 述, 本文所指的蓝藻水华为: 在富营养化水体中, 在一定的气象条件下, 某些藻类大量繁殖并聚集, 并在水面 形成或薄或厚的绿色或其他颜色的藻类漂浮物的现象.

1.1.2 遥感数据 环境减灾星 $1 \mathrm{~A} / \mathrm{B}$ ( 以下简称 $\mathrm{HJ}$ 卫星) CCD 传感器分辨率高达 $30 \mathrm{~m}$, 拥有可见光蓝、绿、红 和近红外 4 个通道, 当二者联合观测时, 重访周期仅为 2 天, 可对滇池蓝藻水华是否发生进行有效监测. 为 了保证监测结果的可靠性以及数据的可获取性, 本文以 2010-2011 年间中午过境的逐日 HJ 卫星 1A/B CCD 影像为主, MODIS-TERRA 卫星 $250 \mathrm{~m}$ 和 $500 \mathrm{~m}$ 影像为辅进行蓝藻水华信息提取.

1.1.3 蓝藻水华提取方法 大量藻类聚集在水体表面, 使水体反射率在近红外波段急剧上升, 形成类似植被 的“陡坡效应”, 与清洁水体在该波段较强的吸收形成强烈反差,这一特征为利用遥感方法监测蓝藻水华提 供理论依据. 目前常用的水华遥感监测方法主要有假彩色合成、波段比值、归一化植被指数 (NDVI)、增强植 被指数 $(E V I)$ 、浮游藻类指数 $(F A I)$ 等 ${ }^{[20-25]}$. 但由于 $\mathrm{HJ}$ 卫星 $\mathrm{CCD}$ 传感器无短波红外通道, 无法计算 $F A I$, 通 过对其他方法的试验, 利用假彩色合成和 $E V I$ 相结合的方法就能达到高效、准确的效果. 具体流程为首先对 HJ 卫星 $1 \mathrm{~A} / \mathrm{B}$ CCD 和 TERRA 卫星 $250 \mathrm{~m}$ 和 $500 \mathrm{~m}$ 通道影像进行辐射定标、投影转换、地理校正和简单大气 校正; 然后 HJ 卫星采用 CCD 传感器 $R: 3 、 G: 4 、 B: 3$, TERRA 采用 $250 \mathrm{~m}$ 通道 $R: 1 、 G: 2 、 B: 1$ 进行假彩色合 成, 为了避开滇池外海湖岸带水生植物的影响, 挑选 HJ 卫星和 TERRA 卫星滇池枯水期影像质量较好和蓝 藻水华未发生的影像分别提取外海水岸线, 再在假彩色合成图上叠加相应的水岸线, 当滇池水岸线以内大 面积发生蓝藻水华时, 仅通过目视解译进行判识, 当目视解译蓝藻水华未发生或不能确定时, 采用 EVI 做进 一步判识, 通过对不同时段两颗卫星的蓝藻水华 $E V I$ 分析, $\mathrm{HJ}$ 卫星判识蓝藻水华的阈值在 0.07 附近波动, TERRA 卫星阈值在 0.13 附近波动, 因此统一采用 $\mathrm{HJ}$ 卫星 $E V I \geqslant 0.07$ 、TERR 卫星 $E V I \geqslant 0.13$ 作为蓝藻水华 判识阈值. 通过 HJ 卫星和 TERRA 卫星假彩色合成和 $E V I$ 对比 (图 1、2), 以 2010 年 8 月 10 日和 31 日 HJ 卫 星和 TERRA 卫星监测结果为例, 二者均在滇池北部监测到水华, 虽然 $E V I$ 将南部云区误判为水华, 但是云 区在假彩色合成图上为白色一灰色, 在判识时较易剔除其影响. 同时 HJ 卫星和 TERRA 卫星监测的水华区域 分布范围基本一致, 由此可见, 利用 HJ 卫星和 TERRA 卫星监测滇池蓝藻水华是可行的. $E V I$ 具体计算方法 如下:

$$
E V I=2.5 \times \frac{\rho_{\mathrm{NIR}}-\rho_{\mathrm{RED}}}{\rho_{\mathrm{NIR}}+6.0 \rho_{\mathrm{RED}}-7.5 \rho_{\mathrm{BLUE}}+1}
$$

式中, $\rho_{\mathrm{NIR}} 、 \rho_{\mathrm{RED}}$ 和 $\rho_{\mathrm{BLEE}}$ 分别代表近红外波段、红光波段和蓝光波段的反射率, 对应 HJ 卫星和 TERRA 卫星分 
别为 4、3、1 通道和 $2 、 1 、 3$ 通道 (其中 3 通道重采样为 $250 \mathrm{~m}$ ).
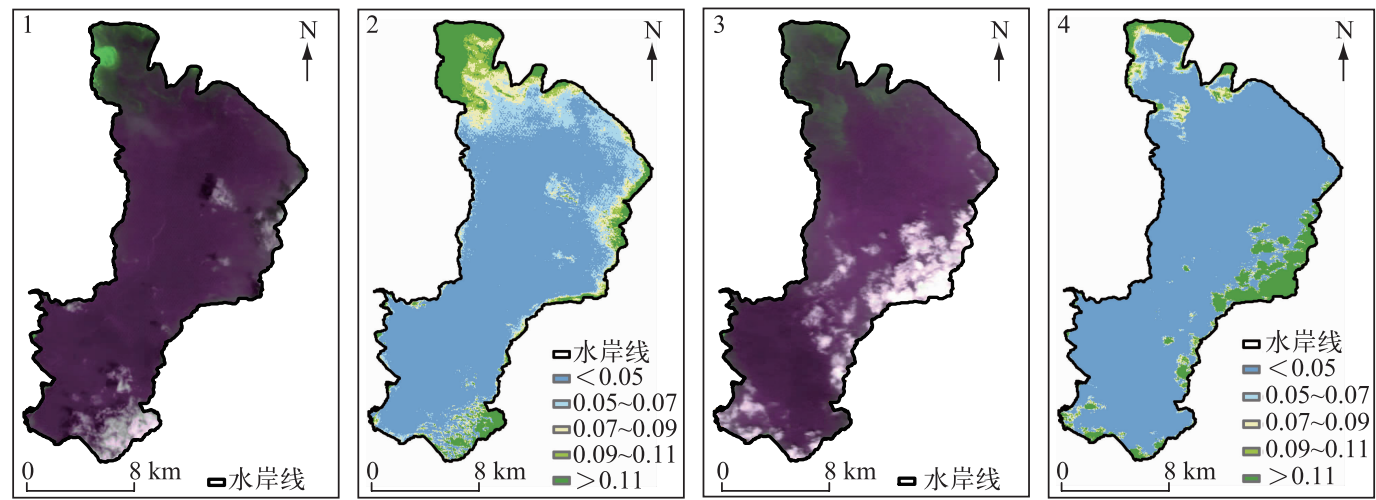

图 12010 年 8 月 10 日和 31 日 HJ 卫星假彩色合成和 $E V I$ 监测对比( 假彩色合成: 1 和 $3, E V I: 2$ 和 4)

Fig. 1 Comparison of false color synthesis and EVI monitoring of HJ satellite on August 10th and 31st, 2010 (false color synthesis: 1 and $3, E V I: 2$ and 4)
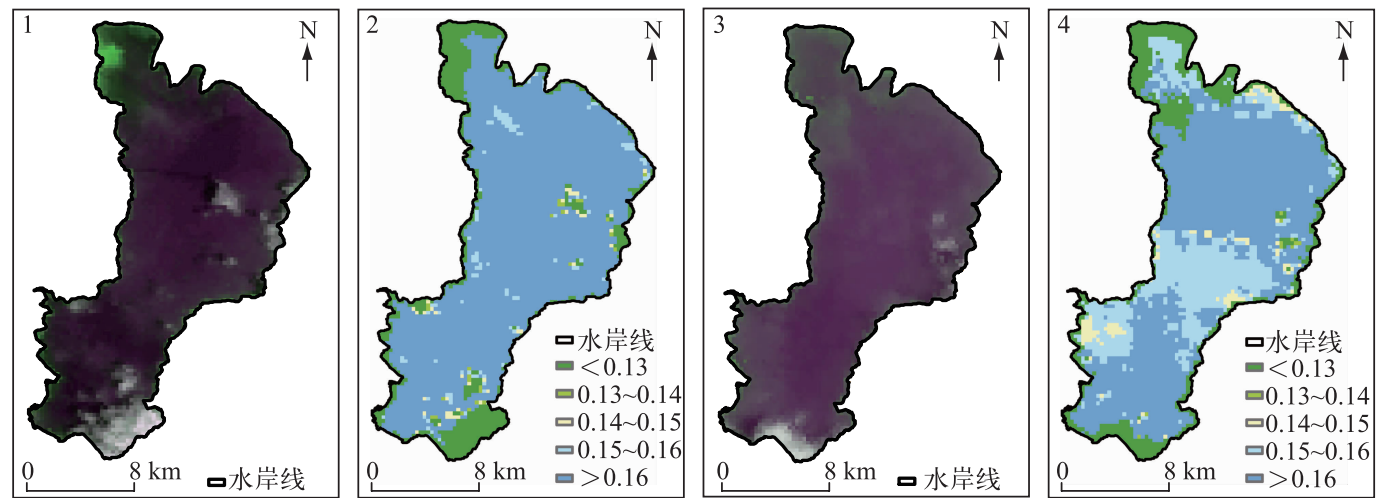

图 22010 年 8 月 10 日和 31 日 TERRA 卫星假彩色合成和 $E V I$ 监测对比(假彩色合成: 1 和 $3, E V I: 2$ 和 4)

Fig.2 Comparison of false color synthesis and EVI monitoring of TERRA satellite on August 10th and 31st, 2010 (false color synthesis: 1 and $3, E V I: 2$ and 4)

1.1.4 蓝藻水华月发生频率的计算方法 卫星资料处理时, 当卫星过境时滇池外海上空完全被云覆盖,或部 分 (主要是外海北部蓝藻高发区) 覆盖并影响蓝藻水华是否发生判识时, 视为无效监测, 当滇池外海大部分 可见, 或者仅部分区域可见且监测到蓝藻水华时, 视为有效监测. 当任意卫星监测到水华, 且面积 $>1 \mathrm{~km}^{2}$ 时, 则认为当日发生了一次蓝藻水华, 反之则认为当日蓝藻水华未发生. 在得到逐日监测结果的基础上, 统计逐 月有效监测次数、水华发生次数和发生频率,当月蓝藻水华发生频率的计算方法为:

$$
P=\frac{n}{N} \times 100 \%
$$

式中, $P$ 为当月蓝藻水华发生频率, $n$ 为蓝藻水华发生次数, $N$ 为有效监测次数.

\section{2 滇池水质数据}

2010-2011 年 1-12 月滇池外海 9 个水质常规监测点月初监测的主要污染物数据(包括 TN、氨氮、TP、 $\mathrm{pH}$ 值、藻密度等监测指标) 由昆明市环境监测中心提供,监测点位分布见图 3.

监测采样方法按《水质采样技术指导》( HJ 494-2009) 规范进行, 监测指标分析方法按《水和废水监测 分析方法》(第四版) ${ }^{[26]}$ 相关标准进行, 各指标具体分析方法见表 1 . 


\section{3 气象数据}

在滇池蓝藻水华与气象因子的相关研究中, 虽然滇池周边有昆明、 呈贡、晋宁和太华山 4 个多因子气象站 (图 4), 但大部分的研究均选择 昆明站气象资料作为气象因子的数据源 ${ }^{[11,24]}$, 由于昆明站位于滇池最 北部, 作为一个整体, 显然仅利用昆明站气象资料代表整个湖区的气象 因子有失偏颇. 因此本研究选择滇池周边 4 个站点气象因子的平均值作 为气象因子的数据源, 所选因子包括 2010-2011 年逐月平均气温、最低 气温、最高气温、气压、降雨量、日照时数、风速和风向频率等. 由于所选 时段仅为两年, 为了排除所选时段气象因子较历年同期可能存在较大差 异导致分析结果无代表性的问题, 对 2000-2011 年和 2010-2011 年 4 个站点平均的逐月平均气温、降雨量、日照时数和风速进行差异性配对 $t$ 检验分析, 分析结果 (表 2) 显示, 所选时段各月与历年同期各要素并无 显著性差异 ( Sig. $>0.05$ ), 说明所选时段各月气象要素具较好的代表性 和适用性.

\section{4 研究方法}

在分析滇池主要水质指标已经不是制约滇池蓝藻水华发生的主要因 子的基础上, 利用逐月统计的 4 个站点气象因子的平均值和滇池蓝藻水 华发生频率, 通过统计分析, 研究滇池水华发生频率与气象因子的关系.

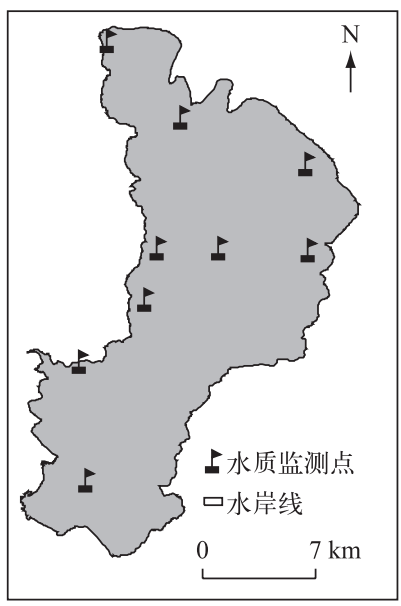

图 3 滇池水质常规监测点分布

Fig.3 Distribution of conventional water quality monitoring points in Lake Dianchi

表 1 监测指标分析方法

Tab.1 Analysis methods of monitoring indicators

\begin{tabular}{ll}
\hline 监测指标 & 分析方法 \\
\hline $\mathrm{TN} /(\mathrm{mg} / \mathrm{L})$ & GB11894-1989 碱性过硫酸钾消解紫外分光光度法 \\
氨氮 $/(\mathrm{mg} / \mathrm{L})$ & GB11892-1989 纳氏试剂比色法 \\
$\mathrm{TP} /(\mathrm{mg} / \mathrm{L})$ & $\mathrm{GB} 11893-1989$ 钼酸铵分光光度法 \\
$\mathrm{pH}$ 值 & GB7859-1987 玻璃电极法 \\
密度 $/\left(\times 10^{4}\right.$ cells $\left./ \mathrm{L}\right)$ & 基于显微镜检测计数的蓝藻苂光快速检测方法 \\
\hline
\end{tabular}

表 $22000-2011$ 年和 2010-2011 年月气象要素差异性分析

Tab.2 Difference analysis of meteorological elements between 2000-2011 and 2010-2011

\begin{tabular}{lrrrrr}
\hline 要素 & 均值 & 标准差 & 均值的标准误 & $t$ & Sig. (双侧) \\
\hline $2000-2011$ 年平均气温/2010-2011 年平均气温 & -0.31 & 0.69 & 0.20 & -1.557 & 0.148 \\
$2000-2011$ 年平均降水量/2010-2011 年平均降水量 & 14.25 & 30.29 & 8.74 & 1.629 & 0.132 \\
$2000-2011$ 年月平均日照时数/2010-2011 年月平均日照时数 & 13.60 & 23.64 & 6.82 & 1.993 & 0.072 \\
$2000-2011$ 年月平均风速/2010-2011 年月平均风速 & 0.10 & 0.24 & 0.07 & 1.489 & 0.164 \\
\hline
\end{tabular}

\section{2 结果与分析}

\section{1 滇池水质分析}

富营养化是蓝藻水华暴发的主要先决条件, 一般来说, 氮和磷被认为是主要的营养元素, 特别是磷对湖 泊富营养化具有特殊的作用 ${ }^{[27]}$. Sas 等对欧洲的 18 个水体进行分析过程中设定, 浮游植物生长在可溶性活 性磷浓度超过 $0.01 \mathrm{mg} / \mathrm{L}$ 的水体中将不受磷限制, 无机氮浓度超过 $0.1 \mathrm{mg} / \mathrm{L}$ 将不受氮限制 ${ }^{[3]}$. 美国国家环 境保护局 (USEPA) 在其《湖泊与水库技术指导手册一营养盐标准》中指出, 在湖泊与水库中, TP 与 TN 浓度 分别超过 1 和 $150 \mu \mathrm{g} / \mathrm{L}$ 时即有可能发生蓝藻水华. 磷浓度高时有利于形成蓝藻水华的种类成为优势种 ${ }^{[28]}$.

从滇池 2010-2011 年的 TN 和 TP 监测情况来看, 滇池 TN 和 TP 浓度最低值均明显高于上述标准( 图 


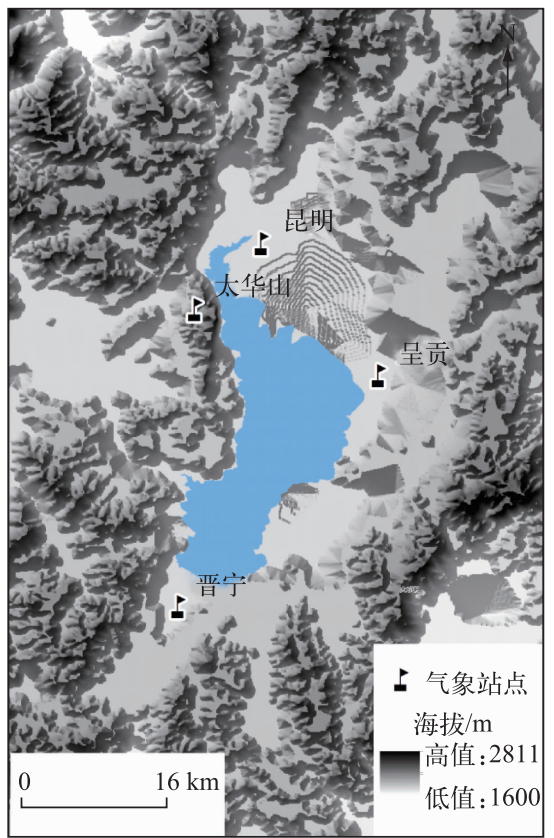

图 4 滇池周边气象站点分布

Fig.4 Location of the meteorological stations around Lake Dianchi
5). 因此在研究时段内, 水体营养盐浓度不是滇池蓝藻水华 暴发的主要限制因子.

此外水体氮磷浓度比对蓝藻水华的发生也有影响. 目前 有两种观点, 其一是随着水体中磷浓度的增加, 通常当 $\mathrm{TN}$ : $\mathrm{TP}<29: 1$, 甚至低至 $5: 1 \sim 10: 1$ 时, 蓝藻在浮游植物种群组成 中占优势 ${ }^{[5-7]}$, 从滇池 2010-2011 年监测情况来看, 滇池氮 磷浓度比在 $13.1: 1 \sim 20.6: 1$ 之间. 因此水体氮磷比也不是滇 池蓝藻水华暴发的限制因子.

同时有研究表明,水体的 $\mathrm{pH}$ 值也会对蓝藻水华的发生 产生影响. 在浮游植物密度较高的水体中, 较强的光合作用 消耗水体中大量 $\mathrm{CO}_{2}$, 因此蓝藻水华发生时伴随了 $\mathrm{CO}_{2}$ 浓度 降低与 $\mathrm{pH}$ 值上升 ${ }^{[29]}$. An 等 ${ }^{\left[{ }^{[30]}\right.}$ 对 Taechung 水库 1994 年夏 季蓝藻生长的研究表明, $\mathrm{pH}$ 值 $>8.5$ 有利于蓝藻的生长, 在 $\mathrm{pH}$ 值 $>9$ 时,微囊藻借助悬浮机制在水体表面形成水华后有 利于吸收 “空气一水” 界面的 $\mathrm{CO}_{2}$, 而其他没有悬浮机制的藻 类, 由于缺乏赖以维持较高光合作用速率的 $\mathrm{CO}_{2}$ 而在竞争中 处于劣势 ${ }^{[6]}$. 从滇池 $\mathrm{pH}$ 值年际变化来看, 滇池常年的 $\mathrm{pH}$ 值 约为 9.0 , 有利于蓝藻的生长, 因此 $\mathrm{pH}$ 值也不是滇池蓝藻水 华暴发的限制因子.

滇池水体氮、磷浓度极高, $\mathrm{pH}$ 值为蓝藻水华发生的最适 范围,各项指标均达到或突破了蓝藻水华发生的阈值,因此, 可以把滇池看成一个蓝藻水华发生与气象因子关系的天然 实验体.

\section{$2.22010-2011$ 年滇池蓝藻水华时间分布规律}

监测结果显示, 2010-2011 年的 249 次有效监测中,共发生蓝藻水华 89 次,占有效监测总数的 $35.7 \%$. 2010 和 2011 年分月统计显示,除 $1 、 2 、 6$ 和 8 月发生频率大致相当外 (2010 和 2011 年 1 月均为 0,2 月分别 为 $8.3 \%$ 和 5.9\%,6 月均为 50\%,8 月均为 100\% ), 其他各月发生频率差异较大. $2010-2011$ 年综合统计显 示, 滇池蓝藻水华呈现前低、中高、后下降的趋势. 其中 1-3 月发生频率在 8\%以下, 6、10 和 11 月发生频率 为 50\%, 发生频率较高的为 7-9 月,其中 8 月发生频率为 100\% (图 6).

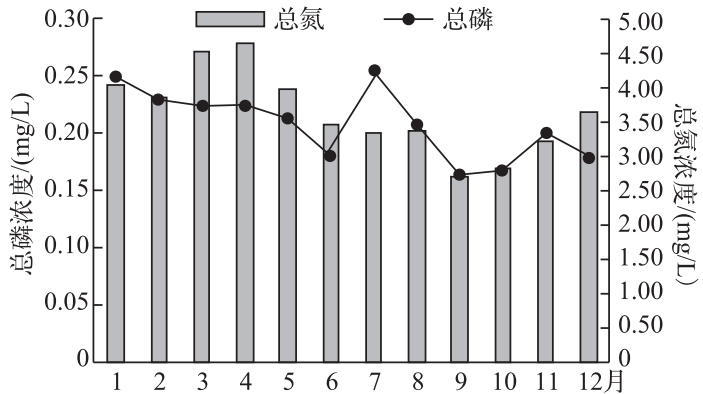

图 5 滇池 2010-2011 年 $1-12$ 月全湖 $\mathrm{TN}$ 和 TP 浓度变化

Fig.5 Variations of total nitrogen and total phosphorus concentrations from January 2010 to December 2011 in Lake Dianchi

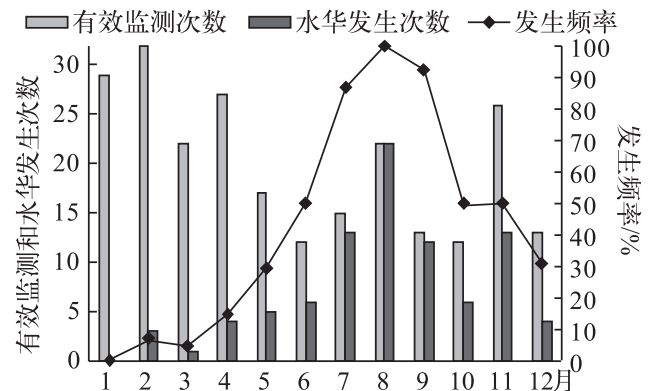

图 6 滇池 2010-2011 年逐月蓝藻 水华遥感监测统计

Fig.6 Monthly statistics of cyanobacteria bloom by remote sensing monitoring from 2010 to 2011 in Lake Dianchi 
在水质状况基本不变的情况下，2010-2011 年各月气象条件的差异可能是导致 3-5 月、7 月和 10-12 月蓝藻水华发生频率差异较大的主要原因. 如 2010 年 3-5 月蓝藻水华发生频率较 2011 年明显偏低,气象 因子显示, 2010 年 3-5 月较 2011 年总体月平均气温偏高, 日照时数偏多、风速偏大. 因此有必要进一步研 究各月气象因子与滇池月蓝藻水华发生频率的关系.

\section{3 滇池蓝藻水华月发生频率与月气象因子的关系}

利用这 4 个站点 2010-2011 年逐月平均气温、最高气温、最低气温、累计日照时数、累计降雨量、平均风 速、平均气压等气象因子,与 2010-2011 年逐月滇池蓝藻水华发生频率做相关分析,结果表明,4 个站点最 低气温、日照时数、降雨量和风速均与蓝藻水华发生频率在 0.01 水平呈显著相关, 其中与最低气温和降雨量 呈正相关 (相关系数分别为 0.611 和 0.719 ), 而与日照时数和风速呈负相关 (相关系数分别为 -0.724 和 -0.783 ), 与平均气温在 0.05 水平呈显著正相关 (相关系数为 0.513 ); 相关系数最高的为风速, 表明滇池蓝藻 水华发生与风速关系最为密切. 最高气温和气压未通过显著性检验 (相关系数分别为 0.388 和 0.049 ), 表明 滇池蓝藻水华月发生频率与月最高气温和平均气压的相关性较低.

2.3.1月平均最低气温 $2010-2011$ 年滇池月平均最低气温 $1-7$ 月逐渐升高, 7 月最高, 从 8 月开始逐渐降 低; 蓝藻水华发生频率从 1 月开始逐渐升高, 8-9 月达到顶峰, 此后从 10 月开始逐渐降低 (2010 年 11 月除 外), 蓝澡水华发生频率的变化趋势与最低气温的变化趋势相似,但是相对月最低气温具有一定的滞后性 (图 7a). 因此可用 1 月的月平均最低气温与 2 月的蓝藻水华发生频率, 2 月的月平均最低气温与 3 月的蓝 藻水华发生频率, 以此类推,建立回归模型. 其意义在于利用该模型可实现当月最低气温预测下月蓝藻水华 发生频率. 从散点图及回归分析的结果可以看出, 线性回归得到 $R^{2}$ 高达 0.6651 (图 7b). 依据该模型, 当上月 平均最低气温低于 $4.3^{\circ} \mathrm{C}$ 时, 滇池蓝藻水华不会发生, 当月平均最低气温升至 $12.1^{\circ} \mathrm{C}$ 时, 滇池蓝藻水华可能 发生的频率升至 $50 \%$, 当月平均最低气温升至 $19.9^{\circ} \mathrm{C}$ 时, 滇池蓝藻水华可能发生的频率升至 $100 \%$ 。
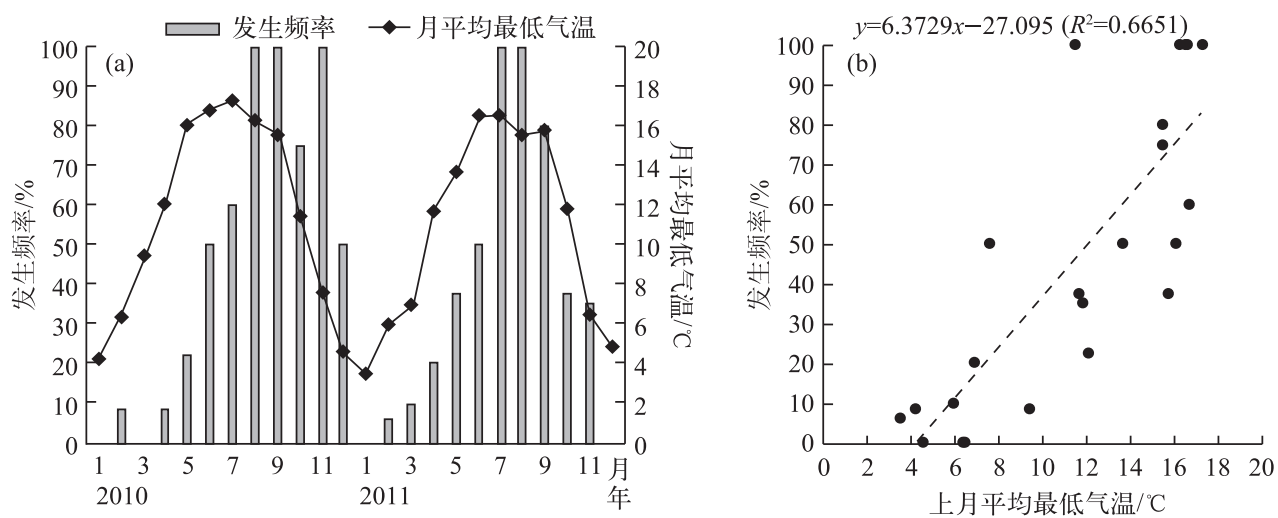

图 7 蓝藻水华发生频率与月平均最低气温的对比 (a) 及与上月平均最低气温的散点图 (b)

Fig.7 Comparison of the occurrence frequency of cyanobacteria bloom and the monthly average minimum temperature (a), and the scatter plot (b)

2.3.2月平均气温 2010- 2011 年滇池各月平均气温与月平均最低气温变化趋势基本一致(图 7a、8a). 用 同样的分析方法做线性回归,得到 $R^{2}=0.5587$ (图 $8 \mathrm{~b}$ ), 比月平均最低气温所得 $R^{2}$ 低, 说明月平均最低气温 对蓝藻水华发生频率的影响高于月平均气温.

2.3.3 月日照时数 2010-2011 年滇池日照时数在 1-5 月较 6-10月长, 在日照时数较长的 $1-4$ 月, 对应 的蓝藻水华发生频率反而较低; 而在日照时数非常短的 6-10月,对应的蓝藻水华发生频率反而非常高 (图 9a). 两者的相关性分析结果表明,年内各月蓝藻水华发生频率与各月的平均日照时数呈显著负相关,相关 系数为-0.724. 进一步对蓝藻水华发生频率与日照时数做散点图及回归分析, 回归分析结果 $R^{2}=0.5245$ (图 9b).

2.3.4 月降雨量 随着月降雨量的增大, 滇池蓝藻水华发生频率呈增大趋势 (图 10a). 两者的相关性分析结 

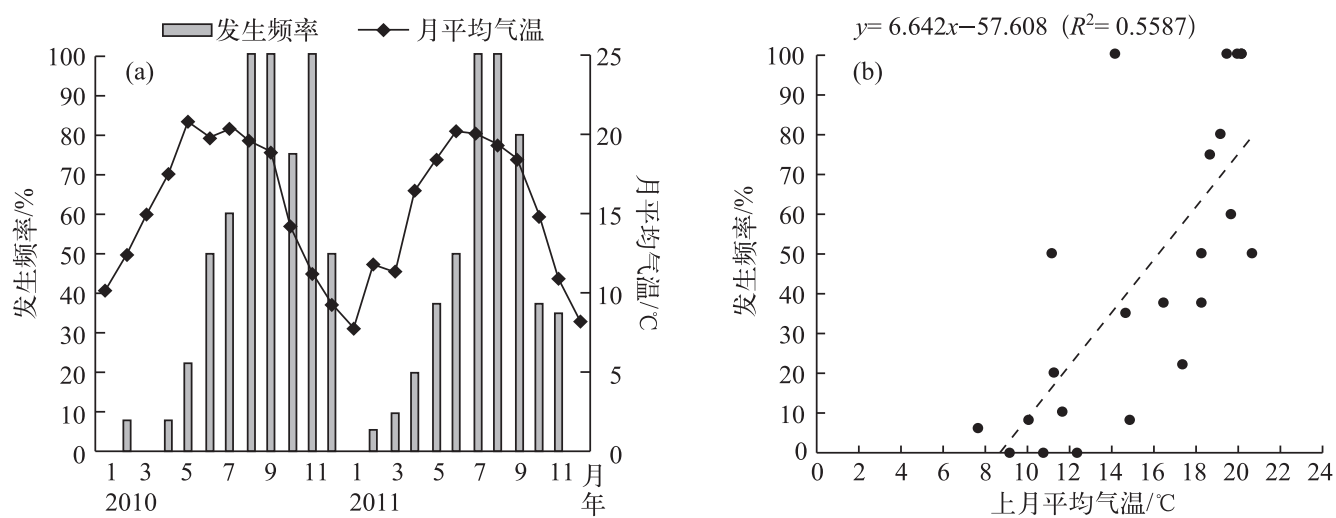

图 8 蓝藻水华发生频率与月平均气温的对比 (a) 以及与上月平均气温的散点图 (b)

Fig. 8 Comparison of the occurrence frequency of cyanobacteria bloom and the monthly average temperature (a), and the scatter plot (b)
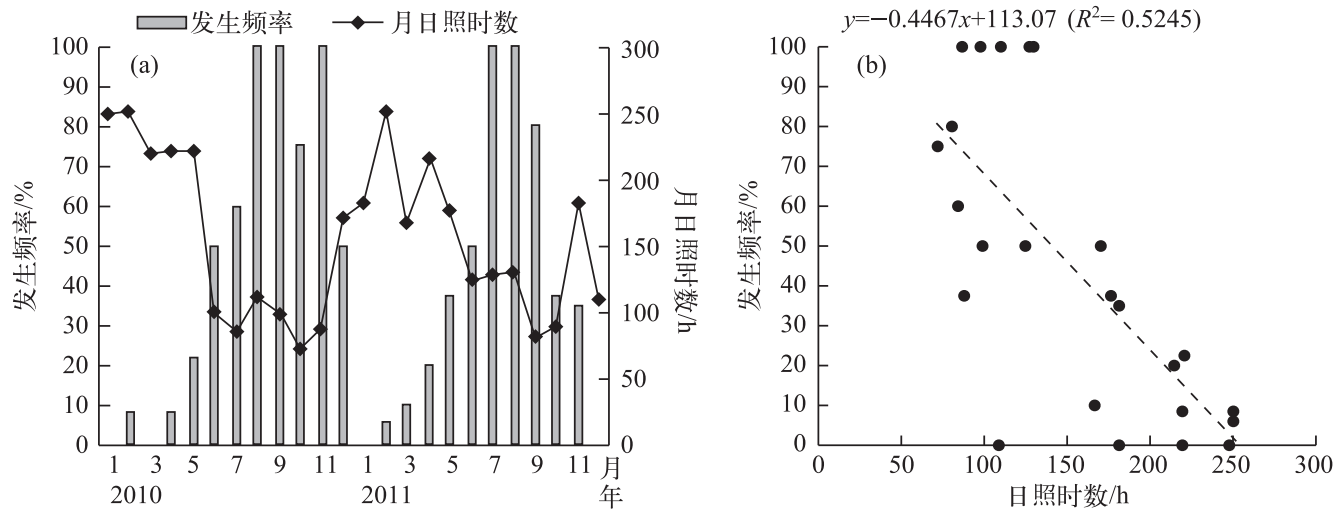

图 9 滇池蓝藻水华发生频率与月日照时数的对比 (a) 和散点图 (b)

Fig.9 Comparison of the occurrence frequency of cyanobacteria bloom and the monthly sunshine hours (a), and the scatter plot(b)

果表明, 年内各月蓝藻水华发生频率与各月的降雨量呈显著正相关, 相关系数为 0.719 . 进一步对蓝藻水华 发生频率与月降雨量做散点图及回归分析, 发现降雨量与滇池的藻类水华之间存在显著正相关关系, $R^{2}=$ 0.5169 (图 10b).

2.3.5 平均风速 滇池月平均风速在 1-4 月均大于 $2.5 \mathrm{~m} / \mathrm{s}$, 对应的蓝藻水华发生频率较低; 在 5-9 月随着 风速的减小, 对应的蓝藻水华发生频率有增加的趋势 (图 11a). 对蓝藻水华发生频率与平均风速的倒数做 散点图及回归分析, 可以看出平均风速的倒数与滇池的藻类水华之间存在显著的正相关关系, 回归分析结 果 $R^{2}=0.6812$ (图 $11 \mathrm{~b}$ ). 依据该模型, 当月平均风速高于 $3.7 \mathrm{~m} / \mathrm{s}$ 时, 滇池蓝藻水华不会发生, 当月平均风速 降至 $2.2 \mathrm{~m} / \mathrm{s}$ 时, 滇池蓝藻水华可能发生的频率升至 $50 \%$, 当月平均风速降至 $1.5 \mathrm{~m} / \mathrm{s}$ 时, 滇池蓝藻水华可能 发生的频率升至 $100 \%$.

\section{3 讨论和结论}

研究认为, 影响蓝藻水华的主要因子有水体氮磷浓度、氮磷比、 $\mathrm{pH}$ 值, 水温、水动力和气象因子等因 子 $^{[1-2]}$. 对于滇池, 以上因子中水动力主要取决于风速的大小, 水温主要取决于气温高低和日照时数大小, 因 

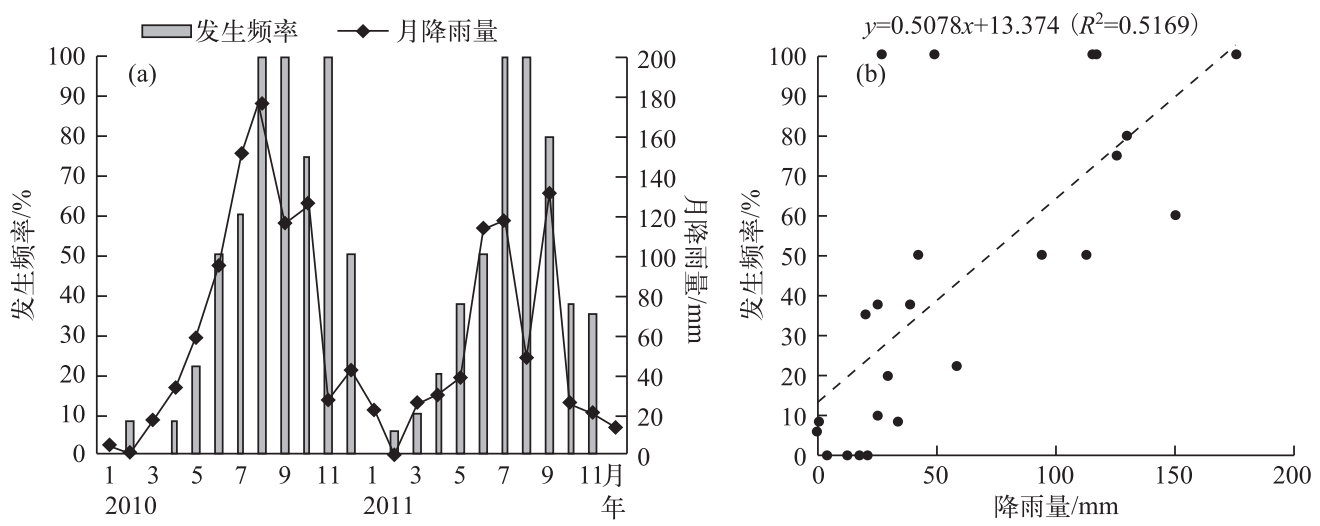

图 10 滇池蓝藻水华发生频率与月降雨量的对比 (a) 和散点图 (b)

Fig.10 Comparison of the frequency of cyanobacteria bloom and the monthly precipitation (a), and the scatter plot (b)
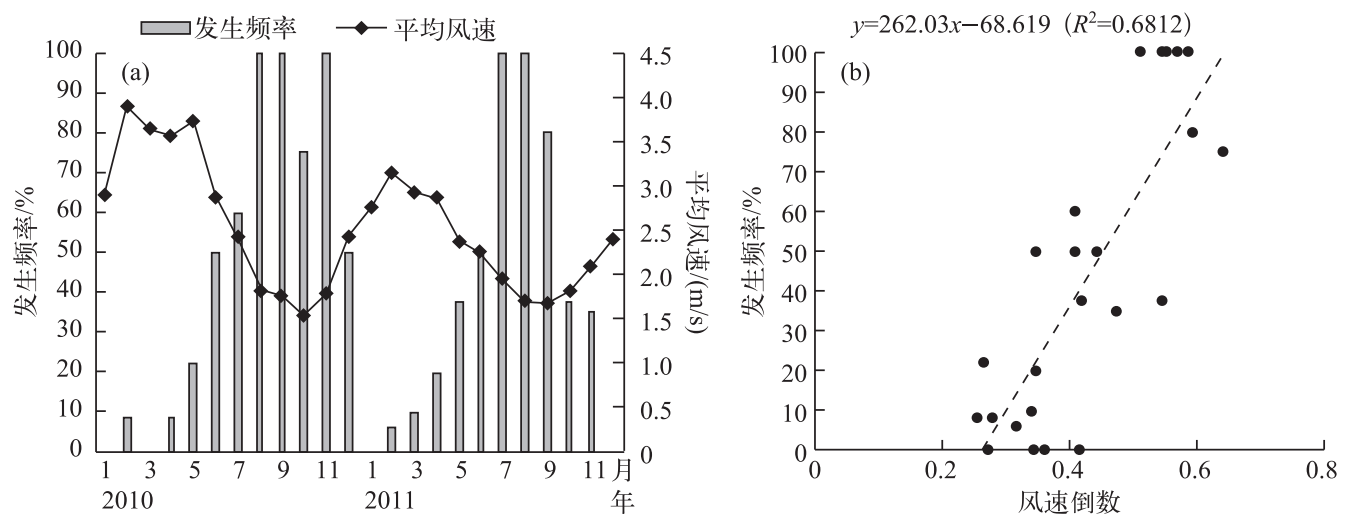

图 11 滇池蓝藻水华发生频率与平均风速的对比 (a) 和散点图 (b)

Fig. 11 Comparison of the frequency of cyanobacteria bloom and the average wind speed (a), and the scatter plot (b)

此这两个因子可归结为气象因子. 本文在分析研究时段滇池水体氮、磷浓度、氮磷比、 $\mathrm{pH}$ 值的基础上, 认为 研究时段内影响滇池蓝藻水华发生的主要因子为气象因子,为后面气象因子对蓝藻水华发生频率的分析排 除了其他因子的影响,所得结果更为客观合理. 同类研究则基本忽略了以上分析 ${ }^{[9,11,32]}$, 以太湖为例, $2008-$ 2012 年逐月水质监测结果 ${ }^{1}$ 显示, 虽然太湖 TN 和 TP 浓度均达到了蓝藻水华发生的阈值上限, 但是氮磷比 在部分月份大于 $29: 1$, 这将成为影响太湖同期蓝藻水华发生的重要因子, 如果仅分析气象因子对蓝藻水华 的影响,所得结果可能存在误差. 建议在做同类研究时,对影响蓝藻水华的因子先做分析, 以确定气象因子 是否为唯一限制因子, 之后的分析结果才更有说服力. 同时这也说明, 气象因子对滇池蓝藻水华影响的重要 性高于太湖.

此外本文的结果和已发表的类似文献还存在以下差异:

1) 在蓝藻水华发生的主要月份方面, 可能由于蓝藻水华多发生在气温较高的季节, 因此大部分研究均 以 5-10 月为主 ${ }^{[11,24,32,34]}$, 容易给读者造成在其他月份蓝藻水华不会发生的误解. 文献 ${ }^{[24]}$ 认为滇池蓝藻水

(1) 水利部太湖流域管理局. 太湖流域及东南诸河省界水体水资源质量状况通报, 2012. 
华发生的关键期为 6-9 月份. 但本文研究结果则显示, 7-9 是滇池蓝藻水华发生的高发期, 发生概率为 90\% 100\%, 6月、10-11 月发生概率为 50\% 左右,5 月和 12 月为 30\% 左右, 其他月份相对较低. 若以月发生 频率 $\geqslant 50 \%$ 为关键期, 那么滇池蓝藻水华发生的关键期应为 6-11 月份.

2) 在温度方面,一般认为, 蓝藻对高温的耐受能力强于其他藻类, 较高的水温有利于蓝藻成为优势种群 和蓝藻水华发生 ${ }^{[33]}$, 有研究指出太湖蓝藻水华暴发的适宜气温为 $22 \sim 33^{\circ} \mathrm{C}^{[31]}$, 同样容易给读者造成在适宜 温度以下蓝藻水华不会发生的误解. 对 89 个监测到蓝藻水华样本当日 12:00 时最高气温进行统计分析, 结 果显示, 仅有 $62.9 \%$ 的样本最高气温在 $22.0 \sim 26.5^{\circ} \mathrm{C}, 31.5 \%$ 的样本在 $15.0 \sim 21.9^{\circ} \mathrm{C}$, 在最高气温仅为 $12.5^{\circ} \mathrm{C}$ 时, 蓝藻水华依然会发生 (图 12). 显然上述适宜气温对滇池蓝藻水华的发生并不适用. 这对于仅从气温方 面界定滇池蓝藻水华是否发生具有重要意义.

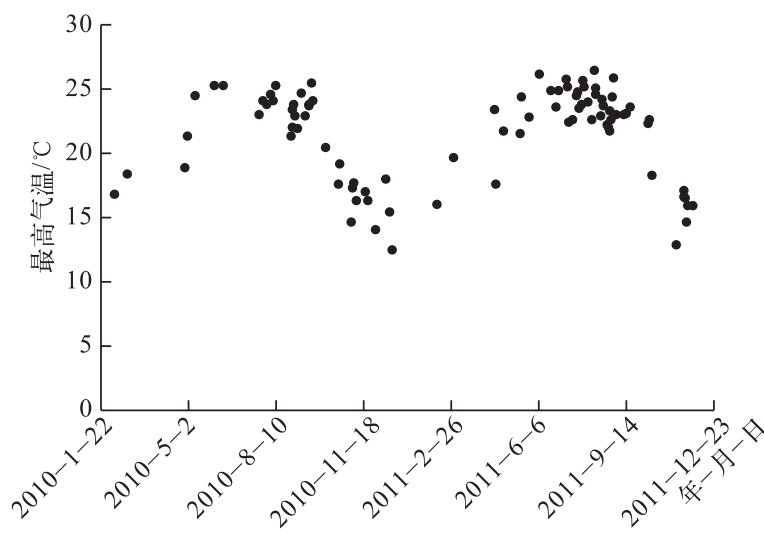

图 12 滇池蓝藻水华发生日的最高温度分布

Fig.12 Distribution of maximum temperature when cyanobacteria bloom occurred in Lake Dianchi

3 ) 在日照时数方面, 文献 ${ }^{[9-11,24]}$ 一致认为日照时数越多, 蓝藻水华就越容易发生, 但是本文研究结果显 示, 蓝藻水华发生频率与日照时数呈显著负相关关系, 即日照时数越少, 蓝藻水华月发生频率越高, 这与前 人的研究结论相反. 对样本数据进行分析后发现,2011年 7 月 11 日、8 月 27 日和 9 月 3 日均监测到蓝藻水 华,但是当日的日照时数为 $0 \mathrm{~h}$, 说明仅在监测时滇池上空恰巧出现了短时的晴空. 究其原因, 可能是前期 ( 1-5 月) 日照时数较多, 蓝藻已经积累了足够的生物量, 在多云和阴雨天气, 只要其他气象条件适宜, 也会 发生蓝藻水华. 此外有研究结果显示紫外辐射对蓝藻生长和光合作用有抑制作用 ${ }^{[35]}$, 由于滇池地处高原, 紫外辐射强度高于地处平原地区的巢湖和太湖, 这也可能是导致本文结论与其他湖泊所得结论相反的原因 之一. 至于文献 $[11,24]$ 虽然所得结论基于滇池数据, 但由于其所用样本数较少, 并未涉及日照时数较少的 样本, 致使结论出现偏差.

4) 在降雨量方面, 有研究认为, 随着降雨量的增加, 雨水会起到相应的稀释作用, 对蓝藻水华发生和水 华面积有一定的抑制作用 ${ }^{[32]}$. 也有研究认为当降水量增加时, 地表径流增多, 将携带陆地上更多的污染物 汇人湖体, 尤其是农田和城镇所在地区的化肥、污水、家畜粪便等, 经人湖河流汇人湖泊, 致使水体营养元素 浓度增加, 促进蓝藻水华的发生 ${ }^{[36]}$. 从本文的研究结果看, 滇池蓝藻水华发生频率与降雨量呈显著正相关 关系, 与后者结论一致, 但从原因来看, 根据前文对滇池水质的分析, 认为营养盐浓度并不是滇池蓝藻水华 暴发的限制因子, 因此本文认为降水通过影响其他气象条件, 而非通过影响营养盐条件而影响滇池蓝藻的 生长.

5) 在风速方面, 风速是滇池水动力和水体稳定性的重要影响因子. 当风浪过大时起到搅拌作用,致使水 体表层蓝藻下沉, 改变藻密度的垂直分布, 使得水体中藻密度趋于均匀, 不易发生水华; 当风速小于临界风 速时, 有利于蓝藻上浮聚集形成水华. 滇池 2010-2011 年的 8 个水质常规监测点藻密度监测情况显示, 全 湖藻密度 $1-12$ 月平均值为 $5833 \times 10^{4}$ cells $/ \mathrm{L}$, 最大值出现在 7 月 $\left(9562 \times 10^{4}\right.$ cells $\left./ \mathrm{L}\right)$, 最小值出现在 2 月 $\left(2087 \times 10^{4}\right.$ cells $\left./ L\right)$, 最大值和最小值之间并未出现明显的数量级增长, 说明滇池常年水体藻密度已经具备 
了蓝藻水华发生的条件. 蓝藻水华月发生频率与月平均风速分析显示, 月发生频率较低的月份正是风速较 高的月份, 表明水体稳定性为制约蓝藻水华发生的主要因子. 此外国内外学者在临界风速对蓝藻水华的影 响方面做了大量研究, 但由于分析方法和研究水体的差异, 所得临界值从 2.0 至 $4.5 \mathrm{~m} / \mathrm{s}$ 不等 ${ }^{[9,11-13]}$. 本文依 据所得模型计算, 月平均风速 $>3.7 \mathrm{~m} / \mathrm{s}$ 时滇池蓝藻水华不会发生, $50 \%$ 发生概率的临界风速为 $2.2 \mathrm{~m} / \mathrm{s}$, $100 \%$ 发生概率的临界风速为 $1.5 \mathrm{~m} / \mathrm{s}$, 进一步明确了滇池蓝藻水华发生与风速的关系, 对于蓝藻水华的防治 具有重要指导意义.

以上分析从单因子方面讨论了本文研究结果与前人研究结论的差异, 较为一致的是较小的风速有利于 蓝藻水华的发生. 从各因子的时段匹配 (图 13) 来看, 虽然冬、春季滇池日照时数较多, 降雨偏少, 但是风速 较大, 致使蓝藻水华在冬、春季节发生频率较低, 夏、秋季则刚好相反. 依据生态学的 “短板” 理论可推断, 风 速是影响滇池蓝藻水华发生的决定性因子. 进一步验证了在具备蓝藻水华发生所需营养盐条件下, 水体稳 定性对蓝藻水华发生的影响更为重要的结论 ${ }^{[34]}$. 而风速与日照和降雨量时段匹配的差异, 也可能是本文在 日照、降雨等方面所得结论有别于其他研究的主要原因.

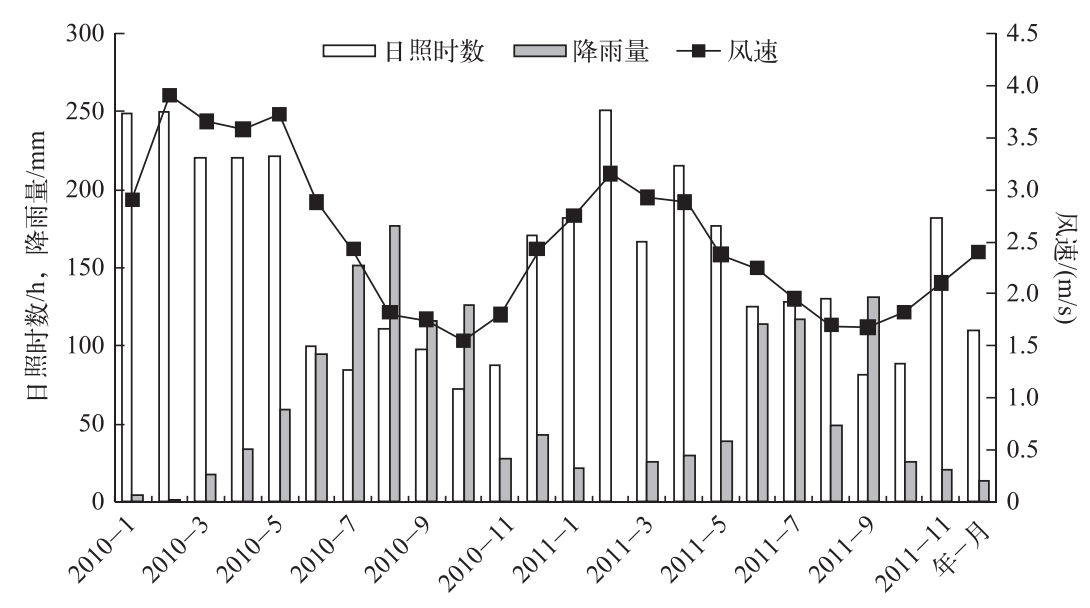

图 13 滇池日照时数、降雨量和风速匹配图

Fig. 13 Matching chart of sunshine hours, precipitation and wind speed at Lake Dianchi

\section{4 参考文献}

[ 1 ] Reynold CS ed. The ecology of freshwater phytoplankton. Cambride studies in ecology. London: Unive Press, 1984.

[ 2 ] Robert EL ed. Phycology ( second edition). London: Cambride Unive Press, 1985.

[ 3 ] Oliver RL, Ganf GG. Freshwater blooms. In: Whitton BA, Potts M eds. The ecology of cyanobacteria. The Netherlands: Kluwer Academic Publishers, 2000: 149-194.

[ 4 ] Smith VH, Tilman GD, Nekola JC. Eutrophication: Impacts of excess nutrient inputs on freshwater, marine, and terrestrial ecosystems. Environmental Pollution, 1999, 100: 179-196.

[ 5 ] Yang Min, Zhang Sheng, Hu Zhengyu et al. Characteristics and preliminary regulating factors of cyanobacterial bloom in Xiangxi Bay of the Three Gorges Reservoir. J Lake Sci, 2014, 26(3) : 371-378. DOI:10.18307/2014.0306. [ 杨敏, 张 晟, 胡征宇等. 三峡水库香溪河库湾蓝藻水华暴发特性及成因探析. 湖泊科学, 2014, 26(3): 371-378.]

[ 6 ] Ma JR, Brookesc JD, Qin BQ et al. Environmental factors controlling colony formation in blooms of the cyanobacteria $\mathrm{Mi}$ crocystis spp. in Lake Taihu, China. Harmful Algae, 2014, 31(1) : 136-142.

[ 7 ] Ndong M, Bird D, Nguyen T et al. Estimating the risk of cyanobacterial occurrence using an index integrating meteorological factors: Application to drinking water production. Water Research, 2014, 56(1) : 98-108.

[ 8 ] Paerl HW, Hall NS, Calandrino ES. Controlling harmful cyanobacterial blooms in a world experiencing anthropogenic and climatic-induced change. Science of the Total Environment, 2011, 409: 1739-1745. 
[9] Fan Yuxiang, Jin Shejun, Zhou Pei et al. Analysis on the distributions and meteorological conditions of cyanobacteria bloom in Chaohu Lake. Journal of Anhui Agricultural Sciences, 2015, (4) : 191-193, 198. [范裕祥, 金社军, 周培等. 巢 湖蓝藻水华分布特征和气象条件分析. 安徽农业科学, 2015, (4) : 191-193,198.]

[10] Reynolds CS ed. The ecology of phytoplankton. Cambridge: Cambridge University Press, 2006.

[11] Li Meng, Xie Guoqing, Lu Weikun et al. Effect of meteorological conditions on blue algal bloom distribution in Dianchi Lake. Scientia Meteorologica Sinica, 2011, 31(5): 639-645. [李蒙, 谢国清, 鲁韦坤等. 气象条件对滇池水华分布的 影响. 气象科学, 2011, 31(5): 639-645.]

[12] Huang CC, Li YM, Yang H et al. Detection of algal bloom and factors influencing its formation in Taihu Lake from 2000 to 2011 by MODIS. Environmental Earth Sciences, 2014, 71(8) : 3705-3714.

[13] Cao HS, Kong FX, Luo LC et al. Effects of wind and wind-induced waves on vertical phytoplankton distribution and surface blooms of Microcystis aeruginosa in Lake Taihu. Journal of Freshwater Ecology, 2006, 21 : 231-238.

[14] Hunter P, Tyler A, Willby $\mathrm{N}$ et al. The spatial dynamics of vertical migration by Microcystis aeruginosa in a eutrophic shallow lake: A case study using high spatial resolution time-series airborne remote sensing. Limnol Oceanogr, 2008, 53: 2391-2406.

[15] Wu T, Qin B, Zhu G et al. Dynamics of cyanobacterial bloom formation during short-term hydrodynamic fluctuation in a large shallow, eutrophic, and wind-exposed Lake Taihu, China. Environmental Science \& Pollution Research, 2013, 20 : 8546-8556.

[16] Qin Boqiang, Yang Guijun, Ma Jianrong et al. Dynamics of variability and mechanism of harmful cyanobacteria bloom in Lake Taihu, China. Chinese Science Bulletin, 2016, 61: 759-770. [秦伯强,杨桂军,马健荣等.太湖蓝藻水华“暴发” 的动态特征及其机制. 科学通报, 2016, 61: 759-770.]

[17] Lu Dayuan, Liu Peigang, Fan Tianyu et al. The investigation of "water bloom' in the downstream of the Han River. Research of Environmental Sciences, 2000, 13(2): 29-31. [ 卢大远, 刘培刚, 范天俞等. 汉江下游突发“水华” 的调查研 究. 环境科学研究, 2000, 13(2): 29-31.]

[18] Zheng Jianjun, Zhong Chenghua, Deng Chunguang. Discussion on definition of algal bloom. Water Resources Protection, 2006, 22 (5) : 45-47，80. [郑建军，钟成华，邓春光. 试论水华的定义. 水资源保护，2006，22(5) : 45-47，80.]

[19] Cao Qiaoli, Huang Yuling, Chen Mingxi. Experimental research on hydro-dynamic simulation of cyanobateria bloom outbreak and extinction. Disaster and Control Engineering, 2008, (1)：8-10. [ 曹巧丽, 黄钰玲, 陈明曦. 水动力条件下蓝 藻水华生消的模拟实验研究与探讨. 灾害与防治工程, 2008, (1) : 8-10.]

[20] Xu Jingping, Zhang Bai, Li Fang et al. Detecting modes of cyanobacteria bloom using MODIS data in Lake Taihu. J Lake $S c i, 2008,20(2)$ : 191-195. DOI: 10.18307/2008.0209. [徐京萍, 张柏, 李方等. 基于 MODIS 数据的太湖藻华水体 识别模式.湖泊科学, 2008, 20(2) : 191-195.]

[21] Zhou Liguo, Feng Xuezhi, Wang Chunhong et al. Monitoring cyanobacteria bloom based on MODIS data in Lake Taihu. $J$ Lake Sci, 2008, 20(2) : 203-207. DOI:10.18307/2008.0211. [周立国, 冯学智, 王春红等. 太湖蓝藻水华的 MODIS 卫星监测.湖泊科学, 2008, 20(2) : 203-207.]

[22] Jin Yan, Zhang Yong, Niu Zhichun et al. Application of Environmental Satellite HJ-1 CCD data for cyanobacteria bloom remote sensing in Taihu Lake. The Administration and Technique of Environmental Monitoring, 2010, 22(5) : 53-56. [ 金 焰, 张咏, 牛志春等. 环境一号卫星 CCD 数据在太湖蓝藻水华遥感监测中的应用. 环境监测管理与技术, 2010, $22(5)$ : 53-56.]

[23] Lu Weikun, Xie Guoqing, Yu Lingxiang et al. Distribution of Bluealga Bloom over Dianchi Lake Monitored with MODIS remote sensing images. Meteorological Science and Technology, 2009, 37(5): 618-620. [鲁韦坤, 谢国清, 余凌翔等. MODIS 遥感监测滇池蓝藻水华分布. 气象科技, 2009, 37(5): 618-620.]

[24] Xie Guoqing, Li Meng, Lu Weikun et al. Spectral features, remote sensing identification and breaking-out meteorological conditions of algal bloom in Lake Dianchi. J Lake Sci, 2010, 22(3) : 327-336. DOI: 10.18307/2010.0304. [谢国清, 李 蒙, 鲁韦坤等. 滇池蓝藻水华光谱特征、遥感识别及暴发气象条件. 湖泊科学, 2010, 22(3): 327-336.]

[25] Hu C, Lee Z, Ma R et al. Moderate resolution imaging spectroradiometer (MODIS) observations of cyanobacteria blooms in Taihu Lake, China. Journal of Geophysical Research: Oceans, 2010, 115(C04002). DOI:10.1029/2009JC005511.

[26] “Water and wastewater monitoring and analysis method" editorial board of State Environmental Protection Administration of China ed. Monitoring and analysis methods of water and wastewater: fourth edition. Beijing: China Environmental Science 
Press, 2002:102-653. [ 国家环境保护总局《水和废水监测分析方法》编委会. 水和废水监测分析方法: 第 4 版. 北 京: 中国环境科学出版社, $2002: 102-653$.]

[27] Hornberger GM, Spear RC. Eutrophication in Peel Inlet-I. The problem-defining behavior and a mathematical model for the phosphorus scenario. Water Research, 1980, 14(1): 29-42.

[28] Reynolds CS, Oliver RL, Walsby AE. Cyanobacterial dominance: The role of buoyancy regulation in dynamic lake environments. New Zealand Journal of Marine \& Freshwater Research, 1987, 21 : 379-390.

[29] Zhao Mengxu, Han Boping. Analysis of factors affecting cyanobacteria bloom in a tropical reservoir ( Tangxi Reservoir, China). Acta Ecologica Sinica, 2005, 25(7): 1554-1561. [赵孟绪, 韩博平. 汤溪水库蓝藻水华发生的影响因子分 析. 生态学报, 2005, 25(7): 1554-1561.]

[30] An KG, Jones JR. Factor regulating blue-green dominance in a reservoir directly influenced by the Asian monsoon. Hydrobiologia, 2000, 432: 37-48.

[31] Robarts RD, Zohary T. Temperature effects on photosynthetic capacity, respiration, and growth rates of bloom-forming cyanobacteria. Marine and Freshwater Research, 1987, 21 : 391-399.

[32] Wu Shengli, Liu Cheng, Sun Jun et al. Remote sensing and analysis on meteorological factors of blue algal bloom in Lake Tai. Meteorological Monthly, 2009, 35(1): 18-23. [武胜利, 刘诚, 孙军等. 卫星遥感太湖蓝藻水华分布及其气象影 响要素分析. 气象, 2009, 35(1):18-23.]

[33] Chen Yuwei, Qin Boqiang, Gao Xiyun. Prediction of blue-green algae bloom using stepwise multiple regression between algae \& related environmental factors in Meiliang Bay, Lake Taihu. J Lake Sci, 2001, 13( 1) : 63-71.DOI: 10.18307/2001. 0110. [陈宇炜, 秦伯强, 高锡云. 太湖梅梁湾藻类及相关环境因子逐步回归统计和蓝藻水华的初步预测. 湖泊科 学, 2001, 13(1): 63-71.]

[34] Ren Jian, Jiang Mingshu, Shang Zhaotang et al. Study on the meteorological condition of blue-green algae fast growth in Lake Tai. Scientia Meteorologica Sinica, 2008, 28(2): 221-226. [任健, 蒋名淑, 商兆堂等. 太湖蓝藻暴发的气象条 件研究. 气象科学, 2008, 28(2): 221-226.]

[35] Zhang Yunlin. Progress and prospect in lake optics: A review. J Lake Sci, 2011, 23(4) : 483-497. DOI: 10.18307/2011. 0401. [张运林. 湖泊光学研究进展及其展望. 湖泊科学, 2011, 23(4) : 483-497.]

[36] Jiang Jin, An Na, Zhang Yi et al. Influence of rainfall run-off in hydrologic process on non-point pollution. Journal of Anhui Agricultural Sciences, 2012, (6) : 3529-3531. [蒋金, 安娜, 张义等. 水文过程中降雨径流对非点源污染的影响. 安徽农业科学, 2012, (6):3529-3531.] 